\title{
The "Traditional-Dependant" and
}

\section{"Revisionist" Dispute on the Motivation of \\ Females in Organizations: the Contributions \\ of Maslow and Herzberg}

\author{
Tim R. Miller
}

\section{Introduction}

The women's movement has produced profound changes in American society in recent decades, as reflected in the extent of popular and scholarly writings devoted to gender-based issues. These changes have obviously been felt in political science. Today, pertinent articles, convention sections and panels, journals and books devoted to the study of women are common and seemingly on the rise.

As with any emerging effort, much remains to be done, however. Few scholars, for instance, have responded to Jane Jaquette's "call for political scientists...to give more attention to women's small-group behavior and the politics of everyday life" (Carroll, 1979: 303; see Jaquette, 1976). With a few notable exceptions (see McCourt, 1977; Kranz, 1976; Garcia et al., 1979), studies of women in public life have had a rather narrow focus on the prominent and powerful (or those who would be). Such studies commonly explore women as candidates for high public office, particularly Congress or state legislatures (see Ambrosius and Welch, 1984); their state legislative behavior (see Githens and Prestage, 1978); as members of Congress (see Kincaid-Blair, 1978); as party leaders (see McDonald and Pierson, 1984); or in high administrative office, whether state (see Carroll, 1984) or federal (see Vertz, 1985 and Lewis, 1986). Although the literature includes numerous studies conducted at the local level of government (see Haffron-Bers, 1978), they, too, tend to emphasize local elites, such as city councilwomen, mayors, and sheriffs (see Gruberg, 1984). Accordingly, "there has been very little (work) on non-elite women of any category..." (Carroll, 1979: 303).

The study at hand addresses this vacuum. Its purpose is twofold: (1) to explore the traditional-revisionist "dependence" or "roledifferentiation" theory debate as applicable to non-elite municipal administrators in a largely rural state, and (2) to direct attention specifically to the administrative practices of the female administrators who help run Arkansas' municipalities, about which little is presently known. 


\section{Problem Statement}

The traditional social- and management-sciences view of women in the workplace has been summarized by Neuse:

Women, it is posited, are located in lower organizational echelons because (1) they are more passive, dependent, and amenable to authority than men and

(2) the female role conflict between family and career obligations of ten vitiates the latter (1978: 436).

Men, the early studies suggest, are "more verbally active than women," less likely to defer to a woman's point of view, less likely to accept or view positively the contributions of women, and "are more likely than women to be perceived by other group members as leaders, and to emerge as leaders" (Chernesky, 1983: 135).

These and other differences in male and female behavior "were initially explained by role differentiation theory." According to this traditional view:

Any viable small group supposedly required some members to perform the role of instrumental leader or task specialist, and others to serve as expressive leaders. Men were considered to be appropriate instrumental leaders while women were seen as suitable expressive leaders because of innate characteristics and/or differences in sex role socialization (Chernesky, 1983: 135).

Until recently, role differentiation and theories of a reinforcing bent (e.g., writings on women's personality) have been seized upon to depict women in organizations as "more emotionally passive and dependent than men" (Edwards and Whiting, 1974: 343), more likely to depend on hierarchy and to "follow direction from above" (Simpson and Simpson, 1969), and to be more "conducive to organizational regulation and control" (Toren, 1969: 158).

Revisionist writings since the mid-1970s are having none of this, however. These scholars have challenged the traditional premises and conclusions (see Neuse, 1978; Kotker, 1980; Pearson, 1981; Kravetz and Jones, 1982; Chernesky, 1983; Sapiro, 1983). Feminist scholars, in particular, charge that the traditional view values male behaviors over females, mirrors stereotypes and social myths concerning women, and judges women against standards rooted in male experiences (Kravetz and Jones, 1982: 77). These revisonist critiques:

have led to new perspectives and information on female participation in the workforce. Conceptualizations that define women as biologically predisposed to be dependent, nurturant, and domestic are rejected in favor of those that acknowledge the persuasive influence of sexism on human behavior and social institutions. Assumptions about innate and stable human characteristics are being replaced by investigations of the effects of socialization processes and cultural values on women and men. Assumptions about the universality and inevitability of male dominance and female subordinance are being replaced by analyses of the social and cultural origins 
of gender power relationships and sexual inequality (Kravetz and Jones, 1982: 77).

The traditional-revisionist debate, then, constitutes a major dispute in the literature on women in organizations. This study addresses this dispute with regard to women occupying non-elite career positions in a rurally-based state. As noted earlier, the literature is top-heavy with studies of women in elite positions, which likewise tend to concentrate on urban or large industrialized settings (see Neuse, 1978). The proposition examined in these pages is that the traditional-dependence theory, if powerful in modern America, would tend to underlie the motivation patterns of (a) female municipal administrators occupying non-elite positions (b) in a rurally-based or undeveloped state grounded in elitist, traditionalistic political culture (see Elazar, 1972).

This is a straightforward proposition. Traditional-dependence theory tells us that women occupy lower level government positions because of their role socialization or innate tendencies to defer to men. They are, the theory tells us, motivated by drives of subservience, dependence, and deference. The literature on political culture suggests that such deference would most commonly be exhibited in areas with what has been labeled "traditionalistic political culture." These cultures exhibit "a paternalistic and elitist conception of the commonwealth" in which society itself is "hierarchical. . . as part of the ordered nature of things, authorizing and expecting those at the top of the social structure to take a special and dominant role in government" (Elazar, 1972: 99). It is reasonable, then, to expect women's "innate or socialized" deferential motivation patterns to be particularly pronounced at lower levels of government in localities grounded in traditionalistic political culture, if indeed the traditional model is persuasive.

\section{Methods}

The data examined in the paper are derived from a study of participants in the 1985 Arkansas Municipal Clerks Institute and Training Program, held in Fayetteville in early September. Twentyseven female municipal officials were studied: seven municipal clerks, ten clerk-treasures, eight recorder-treasurers, and one finance officer. These officials occupy "non-elite" positions to the extent that (a) they are not responsible for overall city policymaking, as are the usual objects of elite study (e.g., mayors and city councils), and (b) their duties are primarily ministerial rather than discretionary in nature. These subjects are somewhat (although imperfectly) representative of Arkansas' broader female clerk-treasurer-recorders to the extent that they include a cross-section of ages and experiences, geographical diversity from throughtout the state, and cover the spectrum of community populations (see Table 1).1 Accordingly, the sample provides an appropriate case study for the traditional-revisionist debate. Support for either the traditional or revisionist position among these women will provide an important first step in examining the issue. Follow-up work will obviously be necessary on Arkansas' female 


\section{Table 1}

Populations of Communities Represented

in the Sample of Arkansas Female Municipal Clerks

Community Population

$$
\begin{array}{rr}
\text { Over } & 45,000 \\
20,000 & -44,999 \\
10,000-19,999 \\
4,000-9,999 \\
1,000-3,999 \\
1-\quad 999
\end{array}
$$

\section{Number of Administrators in Sample}

4

3

4

5

7

4

Table 2

Maslow's Needs Hierarchy Scores

for Arkansas Female Municipal Clerks By Category

Physiological-Safety Needs Average,

\section{Compared with Self Esteem-}

Self Actualization Needs Average

Normal Profiles

Increase of 30 points or more

8

29.6

Increase of 20-29 points

Increase of $10-19$ points

Abnormal "Red Flag" Profiles 
clerks as a whole, and ultimately on women across all of municipal and state government in Arkansas.

Utilizing subjects from Arkansas likewise meets the test of being a sample drawn from an underdeveloped or rurally-based population grounded in traditionalistic political culture. Elazar has persuasively traced the cultural roots of the state to the traditionalistic political culture (Elazar, 1972: 84-126; also see Key, 1949). Subsequent commentators have expanded upon Elazar's typology, while generally not straying far from its central thesis (see Savage and Price, 1980). Although the continued validity of Elazar's portrayal of Arkansas is certainly open to debate, the author is satisfied that Elazar has identified the central tenets of that cultural heritage and that any changes over the past 10 to 12 years have been incremental.

The proposition being examined here is tested in light of the mutually-reinforcing motivation theories of two pioneers of organization behavior, Abraham Maslow and Frederick Herzberg. Maslow's work holds that most human behavior traces to a hierarchy of needs which is ordered from the most basic to the most abstract and sophisticated, including (in order of their origin): physiological needs such as foods and shelter; safety and security; affiliation or love; selfesteem; and self-actualization, which is the need for self-fulfillment (Maslow, 1943 and 1954). The utility of Maslow's need-hierarchy lies in its's contention "that an individual will be motivated to engage in behavior which will lead to the fulfillment or satisfaction of the needs which are currently salient to that person" (Feldman and Arnold, 1983: 109). 2 The study at hand gauges the operational needs systems of Arkansas' municipal clerk-treasurer-recorders, based on a tool (i.e., Work Motivation Inventory) utilizing the paired comparison format developed by Hall and Williams for use by the U.S. Office or Personnel Management. 3

The Maslow-based Work Motivation Inventory presents subjects with a series of paired comparison statements. 4 Each statement corresponds with one of the five needs. Respondents are required to award a total of five points to each of the paired statements according to their degree of concern for each, with distributions ranging from 5 (extremely important) through 0 (unimportant), 4-1, 3-2, 2-3, 1-4, or $0-5$. The Inventory is scored by computing the point totals for each subject and comparing her scores on each need with the national averages of the comparison group (20,542 subjects). The highest point totals "reflect not necessarily the level at which (a subject is) currently operating in the meed hierarchy, but those meed systems which are least satisfied and which, consequently, (she is) most concerned about" (Hall and Williams, 1967).

Two patterns are indicative of abnormal motivation patterns. (a) Those scores which vary significantly from the mean of the national comparison group on any single need are abnormal responses and indicate an unusually strong or weak drive on the corresponding need. (b) Responses which do not show a pattern of increasing scores across the five needs (increasing as they approach self-actualization) are abnormal. This is most readily determined by averaging the scores on the two lowest needs and those of the two highest needs. When the latter are 10 or more points higher than the former, respondents are 
operating on normal patterns. Scores which do not demonstrate the minimum 10 point difference represent abnormal patterns in Maslow's terms (Hall and Williams, 1967).

Herzberg takes Maslow a step further. He sees the factors involved with work as being of two varieties, "motivators" and "hygiene (or maintenance) factors." Hygiene factors include such elements as the company rules and regulations, supervision and relationships with the supervisor, working conditions, and salary; motivators involve factors such as achievement, recognition, the work itself, advancement, and growth (Herzberg, 1966). In a manner of speaking, then, Herzberg divides Maslow's five categories roughly in half. Physiological, safety, and some affiliation needs are depicted as hygiene factors; self-esteem, self-actualization, and some aspects of affiliation are portrayed as motivators. 5 Herzberg's extension of Maslow is in his finding that the lower, hygiene-level factors do not produce lasting motivation. Rather, he contends, they produce "movement," as a dog moves when kicked. When the pain subsides, the dog typically repeats the previous behavior; it moved, but was not motivated. Herzberg's motivators (achievement, etc.), on the other hand, produce a lasting desire to continue the preferred behavior pattern. The "motivators" are deeplyrooted internal sources of energy, which MOTIVATE.

The study is based in part on an exercise in Herzberg's Critical Incident Methodology of work experiences, as administered to the sample of female Arkansas clerk-treasurer-records (see Herzberg, 1976: 283-295). Under the Critical Incident Methodology, respondents write brief stories about real-life, job-related events which produced feelings of extreme satisfaction and dissatisfaction in their work, which are interpreted (based on a specific and unique variation of content analysis) by analysts trained in the technique. 6 Herzberg's Critical Incident Methodology tells us whether the subjects are operating as normal profiles--whether or not they are seeking lasting satisfaction in their work based on motivator, rather than hygiene, factors. Together, Herzberg and Maslow help us understand the extent to which these Arkansas municipal employees are pursuing needs which are capable of producing lasting satisfaction, or whether they are suffering from a mismatch between personal needs and organizational ends (e.g., seeking money through work and expecting it to provide personal satisfaction).

The answers to these questions regarding the nature and levels of motivation among Arkansas' clerk-treasurer-recorders will test the study's central thesis. Namely: subservient, deferential, and dependent role types operate on the basis of "lower ordered" need systems. In the context of Maslow and Herzberg, the traditional/role differentiation behavior model will score abnormally because such subjects suffer from mismatched signals. Deferential and dependent role playing, whether the result of innate characteristics or role socialization, results in behaviors which retard the natural progression and maturity (i. e., motivation) of human beings. On the other hand, the revisionist model does not see women as innately passive and dependent. Rather, the revisionist argument sees women and men as motivated by the same needs, albeit acknowledging that women face serious social and cultural obstacles which men seldom if ever confront (e.g., sexism in 
Table 3

Maslow's Job-Related Consequences of Operational Needs

\begin{tabular}{|c|c|c|}
\hline Need & On the Job Preoccupations & Resulting Job Behaviors \\
\hline Self-Actualization & $\begin{array}{l}\text { Proving oneself to oneself, through } \\
\text { challenging and meaningful work, } \\
\text { creativity, personal growth }\end{array}$ & $\begin{array}{l}\text { Focus on the intrinsic merits } \\
\text { of the work itself; require- } \\
\text { ments for autonomy, risk-taking } \\
\text { and freedom to experiment }\end{array}$ \\
\hline $\begin{array}{l}\text { Self Esteem- } \\
\text { Ego Status }\end{array}$ & $\begin{array}{l}\text { Opportunities for advancement, supportive } \\
\text { recognition based on merits, job assign- } \\
\text { ments displaying skills, inclusion in } \\
\text { planning activities }\end{array}$ & $\begin{array}{l}\text { Mature and constructive contri- } \\
\text { butions and achievements }\end{array}$ \\
\hline $\begin{array}{l}\text { Affiliation or } \\
\text { Belongingness }\end{array}$ & $\begin{array}{l}\text { Friendly colleagues, opportunities for } \\
\text { interaction with others, harmonious } \\
\text { interpersonal relations, team membership }\end{array}$ & $\begin{array}{l}\text { Ingratiate the individual to } \\
\text { others, subordinates, colleagues } \\
\text { and superiors }\end{array}$ \\
\hline Safety & $\begin{array}{l}\text { Fringe benefits, such as: hospitalization } \\
\text { insurance, retirement pension plans, } \\
\text { worker compensation, safe working condi- } \\
\text { tions, seniority protections, clear and } \\
\text { consistent performance standards }\end{array}$ & $\begin{array}{l}\text { Unimaginative, overly-compliant, } \\
\text { uncreative, inflexibility, } \\
\text { dependence }\end{array}$ \\
\hline Basic Physiological & $\begin{array}{l}\text { Pleasant working conditions, leisure time, } \\
\text { luxurious personal property, avoidance of } \\
\text { discomfort, increased salary to obtain } \\
\text { creature comforts }\end{array}$ & Immature and unconstructive \\
\hline
\end{tabular}

Source: Hall and Williams, 1967 
institutions, assumptions about the inevitability and universality of male dominance, cultural values favoring men over women, etc.). According to the revisionist writings, women are as innately motivated by the higher order need systems as are men. On the Maslow and Herzberg methodological formats, responses which are consistent with the revisionist model will score as normal profiles reflecting the more mature and independent motivations of these women subjects (Hall and Williams, 1967).

\section{Analysis}

\section{Maslow's Hierarchy of Needs}

The Work Motivation Inventory (Maslow) results for the Arkansas sample are reported in Table 2, which shows the scores comparing the physiological-safety need and self esteem-self actualization need averages. Three significant patterns are evident from the data.

The first pattern is the extent to which the clear preponderance of Arkansas administrators are operating along normal needs systems. The rising scores indicate that among normal profiles, people tend to be least satisfied and most concerned about (and in Maslow's terms, "motivated by") their self-esteem and self-actualization needs. Seventyfour percent (20 of 27) of Arkansas clerk-treasurer-recorders who underwent this exercise exhibited this normal profile. As shown in Table 2, 29.6 percent of the sample exhibited a dramatic increase of 30 points or more between the basic and more sophisticated needs; 33.3 percent showed increases of between 20 and 29 points; 11.1 percent had increases of between 10 and 19 points. As Maslow sees it, these people are all motivated in their work by desires to fulfill their higher self-esteem and self-actualization needs. But do these patterns really matter in terms of actual work performance? And, more importantly in light of the central thesis under examination here, what do the data tell us regarding the traditional-revisionist debate on women's deference?

According to Maslow and his disciples, the data are instructive on both counts. Table 3 summarizes and illustrates the job-related consequences of the needs hierarchy. As shown, Maslow's research contends that workers who function to satisfy physiological needs are preoccupied with earning money as a means of buying food, shelter, and the like. Such motive orientations, he argues, produce behaviors which are immature, unconstructive, and largely short-term regarding the interests of the employing organization. Those workers operating on the safety need tend to have preoccupations with their workrelated fringe-benefits (e.g., health insurance) and remain largely unimaginative in their work. "Motivation" based on the need for pension-plan security, the theory holds, produces uncreative and routine-like behavior which seldom enhance the ends of the organization. Affiliation needs are seen as leading to preoccupations with friendship and resulting behaviors of deference. In other words, motivation patterns geared toward the three lower needs parallel the assumptions of the traditional-deference model of women in organizations. Women who have an innate or socialized need to be 
subservient, deferential and dependent ought to demonstrate lower need motivations in Maslow's terms, but 74 percent clearly do not!

Continuing with Table 3 , self-esteem generates concern for factors such as advancement and recognition based on merit; corresponding job behaviors are mature and constructive contributions to the deeper organization goals and interests. At the most abstract level, workers who are functioning to fulfill their self-actualization needs tend to be preoccupied with proving themselves (to themselves) through challenging work and personal growth. Resulting job behaviors focus on the intrinsic merits of the work itself, such as the degree of autonomy, freedom, and experimentation in the job. At the outset, then, the Arkansas data largely ( 74 percent) rejects the traditionaldeferential view of women in organizations. Simply put, men or women who are motivated at these higher levels "are primed for using more mature behaviors and for making more constructive contributions to the organization's work to extent that the organization can provide...opportunities for need satisfaction" (Hall and Williams, 1967). Such female administrators are anything but the deferential, stereotypical ladies of the traditional model. In Maslow's terms, these women are motivated by the desire to be full partners in the process of local administration and do not exhibit the restraints of the traditional model.

The second important pattern here has to do with the abnormal or "red flag" respondents, those administrators who are functioning on the basis of regressive needs patterns. The scores of these respondents are shown in Table 4. These abnormal patterns are of two varieties, either "the lower level needs are salient" or they are "equally as strong as some higher level need" (Hall and Williams, 1967). Four of the 27 respondents (14.8 percent) in this sample of female Arkansas administrators suffer from these regressive and counterproductive motivation patterns. The first three red flag respondents in Table 4 "differ significantly in (their) need strength from the average person in organizations" (Hall and Williams, 1967), as indicated by the asterisk(s) assigned to their physiological and/or safety scores. The fourth red flag respondent deviates from the norm in her denial of the importance of self-actualization needs, and is included in this category because the physiological score is considerably higher than the selfactualization score, and because the two averages are approximately the same (58 and 62 respectively). In Maslow's terms, these red flag administrators, "are primed for dissatisfaction and preoccupation with peripheral environmental factors which are not really related to your work per se" (Hall and Williams, 1967). Although it would be inappropriate to conclude on the basis of these data that the abnormal responses are caused by the factors of the traditional dependence model, it is nevertheless the case that such deferentially-based motivations would respond to Maslow's methodology in this manner. The 14.8 percent rate is hardly confirmation of the traditional model of women's deference in organizations.

The third significant pattern from Tables 2 and 4 involves the three administrators (11.1 percent of the sample)whose scores are of an inconclusive nature. The first two individuals in the inconclusive category (Table 4) demonstrated overall increases in saliency as they 
Maslow's Needs Hierarchy Scores,

for Respondents with Non-Normal Profiles

$(n=27)$

Needs hierarchy scores for the seven "non-normal" profiles are shown below. "Red flag" profiles are abnormal scores; "inconclusive" scores are neither normal nor abnormal patterns. Three figures are provided for each need system (e.g., physiological, etc.). The figure labeled "Above" indicates scores which are significantly above the national average. According to Hall and Williams (1967), scores above these levels indicate the highly unusual saliency of these needs for the individual. The figure labeled "Below" indicates scores which are just the reverse, unusually irrelevant to the individual in light of the national sample. "Mean" scores (X) indicate the arithmetic mean for over 20,000 people who have taken the exercise, across nearly all types of organizations.

\begin{tabular}{|c|c|c|c|c|c|c|c|c|}
\hline \multicolumn{9}{|c|}{ NEEDS } \\
\hline & $\begin{array}{l}\frac{\pi}{0} \\
\frac{0}{0} \\
0 \\
0 \\
\frac{0}{n} \\
\frac{1}{2}\end{array}$ & 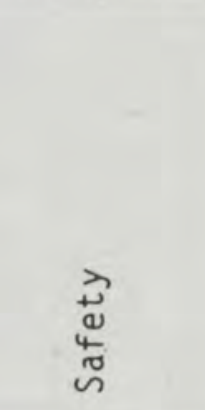 &  & 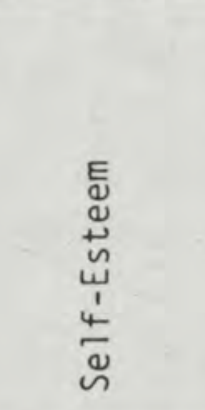 & 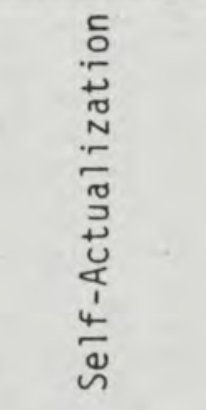 & 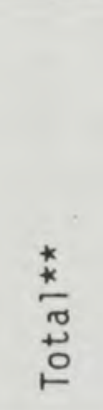 & 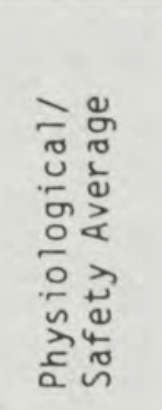 & 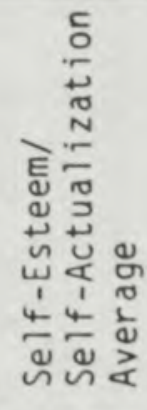 \\
\hline & $\begin{aligned} \text { Above } & =67 \\
\text { Below } & =30 \\
\bar{X} & =48\end{aligned}$ & $\begin{aligned} \text { Above } & =65 \\
B e l o w & =28 \\
\bar{X} & =46\end{aligned}$ & $\begin{aligned} \text { Above } & =71 \\
\text { Below } & =28 \\
\bar{X} & =53\end{aligned}$ & $\begin{aligned} \text { Above } & =93 \\
\text { Below } & =55 \\
\bar{X} & =73\end{aligned}$ & $\begin{aligned} \text { Above } & =99 \\
\text { Below } & =61 \\
\bar{X} & =80\end{aligned}$ & & & \\
\hline $\begin{array}{l}\text { Abnormal } \\
\text { "Red Flag" } \\
\text { Profiles }\end{array}$ & $\begin{array}{l}84^{\star} \\
87^{\star} \\
73^{\star} \\
63\end{array}$ & $\begin{array}{l}72^{\star} \\
22^{\star} \\
53 \\
53\end{array}$ & $\begin{array}{l}52 \\
67 \\
50 \\
60\end{array}$ & $\begin{array}{l}64 \\
65 \\
69 \\
80\end{array}$ & $\begin{array}{l}28 \\
59 \\
51 \\
44\end{array}$ & $\begin{array}{l}300 \\
300 \\
296 \\
300\end{array}$ & $\begin{array}{l}(78) \\
(54.5) \\
(63) \\
(58)\end{array}$ & $\begin{array}{l}(46) \\
(62) \\
(60) \\
(62)\end{array}$ \\
\hline $\begin{array}{l}\text { Inconclusive } \\
\text { Profiles }\end{array}$ & $\begin{array}{l}52 \\
40 \\
58\end{array}$ & $\begin{array}{l}64 \\
62 \\
57\end{array}$ & $\begin{array}{l}50 \\
42 \\
53\end{array}$ & $\begin{array}{l}75 \\
84 \\
68\end{array}$ & $\begin{array}{l}59 \\
60 \\
64\end{array}$ & $\begin{array}{l}300 \\
288 \\
300\end{array}$ & $\begin{array}{l}(58) \\
(51) \\
(57.5)\end{array}$ & $\begin{array}{l}(67) \\
(72) \\
(66)\end{array}$ \\
\hline
\end{tabular}

*Indicates abnormal physiological or safety needs system

$\star \star$ Should equal 300; variation is due to respondent scoring errors. 
moved to the higher needs (average comparisons of 58-67 and 51-72 respectively) which is generally indicative of the more mature motivations, but both are repressing their self-actualization needs. Such behaviors are not normal in Maslow's terms, and are ground for exclusion from the normal profile. The third individual in this category likewise showed an overall increase in needs saliency as she moved up the hierarchy, but to such a moderate extent $(57.5$ and 66 averages) that it is difficult to include the individual in the normal profile.

Overall, the data speak well for both the revisionist view of women and for modern management practices in general among Arkansas' local public-sector administrators. Although Maslow's work is more "classical" than "modern" in the chronological sense, it's emphasis on the viability and general success of administrators who are in touch with their more mature and fulfilling needs--and their power as motivational cornerstones--is quite consistent with the current state of the managerial art. In that context, only 14.8 percent of the local female administrators studied here demonstrated motivation patterns which support the deferential view of women in organizations. In contrast with the 74 percent who are functioning along the more mature and responsible lines, the numbers are again reassuring to the friends of the revisonist view.

\section{Herzberg's Motivation-Hygiene Theory}

As noted earlier, Frederick Herzberg picks up where Maslow leaves off. While Maslow has identified a hierarchy of human needs, Herzberg distinguishes between those needs and circumstances which produce lasting on-the-job "motivation," as opposed to mere "movement."

Over the course of three decades of research, Herzberg has identified 16 factors which are critical in producing job satisfaction and dissatisfaction. These factors are of two types: "the growth or motivator factors that are intrinsic to the job... (and) the dissatisfaction-avoidance or hygiene factors that are extrinsic to the job..." (Herzberg, 1976: 158). Herzberg's research "indicates(s) that motivators were the primary cause of unhappiness on the job" (Herzberg, 1976: 58-59). The hygiene factors produce dissatisfaction, Herzberg writes:

Because man is Adam, and Adam is an animal with an overriding goal to avoid pain from the environment. The hygiene factors describe the job environment. Why do the motivators make man job satisfied? Because man is Abraham, and as Abraham he is a human with an overriding goal to use his human talents for psychological growth, which is the source of human happiness. The motivators are the nutrients for psychological growth. It is what man can accomplish that makes him human, and what he can accomplish on the job will determine his human feelings (Herzberg, 1976: 60).?

Herzberg's job profile, then, provides a second means by which to gauge the traditional-revisionist dispute among Arkansas' female municipal clerk-treasurer-recorders. Simply put, traditional- 
Table 5

Herzberg's Motivation-Hygiene

Factors Affecting Job Attitudes of

Arkansas Female Municipal Clerks

$(n=27)$

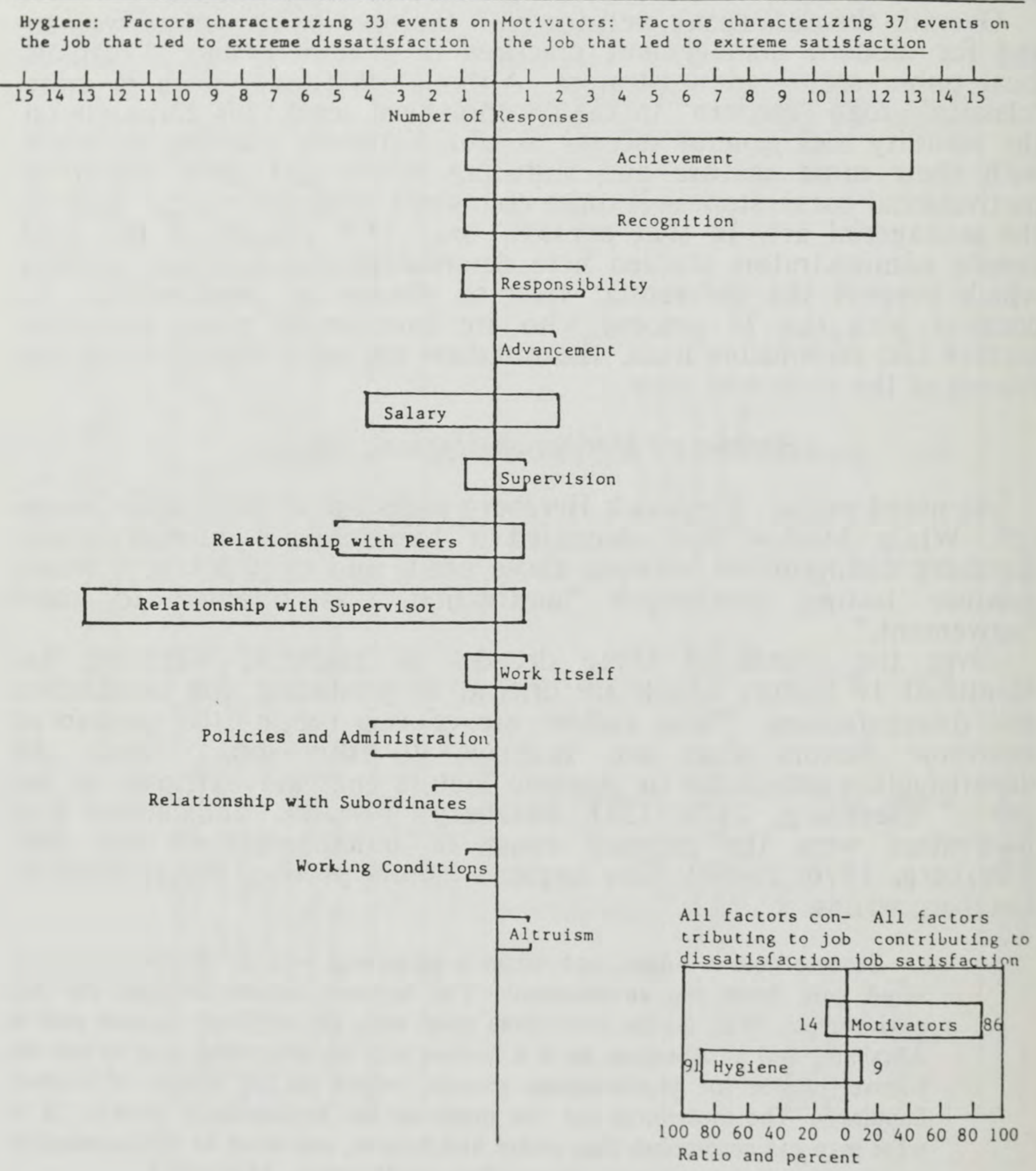


dependence theory suggests that women as administrators will reject what Herzberg sees as the normal tendencies to take satisfaction in the higher, motivating dynamics because those motivators free subjects to pursue the more fulfilling human drives. These drives--particularly greater responsibility, achievement, advancement, and growth--are the antithesis of the motivation patterns underlying traditionaldependence theory. Deferential women (or men) would block or deny these natural drives. Consequently, the traditional-dependent thesis would demonstrate adnormal Critical Incident patterns, which Herzberg has labeled "motivation inversions." 8

As illustrated in Table 5, this sample does indeed yield a normal profile. The Arkansas sample cited 37 motivators as having led to exceptional satisfaction in their jobs, and 33 hygiene factors as having produced exceptional dissatisfaction. The profile is normal in that the leading motivators are associated with job satisfaction, just as leading hygiene factors are associated with job dissatisfaction. Respondent stories yielded 14 instances of "achievement" leading to exceptional feelings, for example; 13 were positive feelings and only one produced job dissatisfaction. As is typical of normal profiles, Arkansas female clerk-treasurer-recorders who were studied are most satisfied in their work by their achievement and recognition for their achievements. Three of the four other motivators were identified (six of eight references produced satisfaction), with "growth" as the only motivator which was not specifically cited by the sample. Likewise, respondents were typical in their dissatisfactions, with one slight variation. In the classic or normal profile, the most common sources of dissatisfaction (in order) are company/organization policies and administration, supervision, and interpersonal relations. Among the Arkansas sample, the leading sources of job dissatisfaction (in order) are interpersonal relations with their supervisor(s) (defined to include mayors and/or city councils), interpersonal relations with peers, and policiesadministration and salary. 9

The Arkansas sample likewise presents a classic profile in that 86 percent of the motivators were cited as having led to job satisfaction, with only 14 percent of the motivators associated with dissatisfaction; 91 percent of the hygiene factors produced dissatisfaction, while a mere nine percent led to dissatisfaction. Motivators leading to dissatisfaction, and hygiene factors leading to satisfaction, are known as "slippages" in Herzberg terminology. Slippage is common to motivation-hygiene studies and traces to three sources, "...experimental error... organizational abnormalities...(and) motivational inversions of the people interviewed" (Herzberg, 1976: 233). The proportion of slippage (i.e., responses which do not fit the model) is "estimated for normal samples to be around 19 percent" (Herzberg, 1976: 232). The Arkansas sample has slippage of 15.7 percent (11 of 70 identifiable factors), which is in keeping with the normal profile.

These findings are particulary useful in light of the previous discussion of Maslow. As noted earlier, 74 percent of Arkansas female clerk-treasurer-recorders in this sample are "motivated" by the higher, more mature needs, with only 14.8 percent functioning on the more regressive and counterproductive needs. The Herzberg data confirm that the vast majority of these female municipal officials do indeed 
base their work orientations on the more sophisticated, higher level dynamics. To that extent, Maslow and Herzberg are speaking in the same terms and their applicability is mutually reinforcing. Still, as has been mentioned earlier, Herzberg has a unique contribution to make to this discussion. Whereas Maslow largely asks the reader to take it on faith that these female administrators, as with workers everywhere, are "motivated" by their unfulfilled needs, Herzberg is more precise. Herzberg has shown that those who operate as Maslow's "red flags" and on the basis of Herzberg's "inversions" and "slippage" ARE NOT MOTIVATED. They respond to short-term stimuli only; they "move" but are not "motivated." These are employees who understand putting in their time and going through the motions. They tend to be quite dissatisfied in their work, are not highly productive, and are generally not the most successful administrative leaders. Reassuringly, they are also in the clear minority among this sample of Arkansas female municipal officials. In contrast, the data presented here are vastly more optimistic. Speaking of the individuals who are pursuing these higher-order sources of satisfaction, Herzberg comments, "it is only when he has his own generator that we can talk about motivation. He then needs no outside stimulation. He wants to do it" (Herzberg, 1976: 55). As the data discussed above have convincingly shown, these female administrators--with a few notable exceptions--are operating on the basis of their own well-emplaced generators. In a word, they are MOTIVATED.

This study's second major test, then, also refutes the traditionaldependence model. This sample of 'Arkansas' female municipal administrators are motivated, in the rich meaning of Herzberg, by opportunities for achievement, recognition, responsibility, and the nature of the work itself. Their job-related pains lie primarily in their relationships with their supervisors (mayors and city councils), peers and subordinates; the administrative policies and rules which they deal with; and their salaries. These hygiene factors have not served to replace, or stifle, the respondents more fulfilling sources of work energy. The vast majority of the sample have not retreated into the deferential "world" as the traditional model suggests they should. The "world" of deference and subservience, after all, is based on the shelter of the supervisor's minimal expectations of employees, protective administrative policies and rules, reinforcing attitudes of peers and subordinates (who are overwhelmingly women in these instances), and--Herzberg would suggest--ill fated attempts to use the hygiene factors (e.g., salary) as the primary source of motivation. In the overwhelming preponderance of cases, exactly the opposite is the case among these women. At the risk of mixing Herzberg's metaphor, these women are Abraham!

\section{Conclusion}

This study has examined the dispute found in the literature on women in organizations between those of the traditional view of women as dependent, deferential, and subservient organization members, and their revisionist critics who contend that any patterns of female deference are unnaturally "imposed" by male-oriented 
society. A departure from most pertinent literature on women in the public sector, the paper examines the motivations of women from a largely rural, nonindustrial state occupying positions which are normally not considered to be elitist in authority. If the traditionaldependent model has validity, it is reasoned, it should be most apparent in such a work setting. Two tests have been employed, measures of Maslow's classic needs hierarchy and Herzberg's motivation-hygiene theory. The findings in both instances lend further support for the revisionist position and contribute to the undermining of the traditional-dependent view of women.

As might be expected, the measures employed here do not universally reject the traditional model. In both exercises, a small minority of respondents demonstrated motivation patterns which are most readily explained by the traditional-dependent model $($ Maslow $=$ 11.1, Herzberg $=15.7$ percent). This is not surprising. Maslow and Herzberg each acknowledge that a significant proportion of workers in nearly all settings have misguided orientations toward themselves and their work; these are regressive orientations which do not motivate. Human behavior, after all, is complex and often misguided. Although it would be inappropriate on the basis of these data to conclude that these counterproductive patterns are caused solely by factors of female deference, proponents of the traditional view would quite likely do so with confidence. More work is obviously called for on the linkage between these minority responses and the traditional model. In the meantime, it is nevertheless appropriate to reject the traditionaldependent thesis in explaining the motivation of these female clerktreasurer-recorders.

\section{Endnotes}

1. It might also be said that they are not representative because those who volunteer for further training, as these officials did, may be the "best and brightest" in their profession. The author acknowledges this possibility, but is undetered by it. If the subjects are the best and brightest municipal clerk-treasurer-recorders in the state, so much the better. It might also be appropriate to add that the dispute being examined here does not distinguish between the best and brightest women and that it is therefore reasonable to assume that the distinction is not terribly relevant.

2. A word or two of caution are in order here. Studies on the validity of Maslow's need hierarchy are inconclusive and generally critical of the extent to which the theory provides a sound basis for understanding human motivation in organizations (see, for instance, Wahba and Birdwell, 1976).

Accordingly, the typology is used here without any assertion that it is a valid theory. Rather, it is applied here for the same reason it is regularly applied in studies of this kind throughout much of the world--including its use by the federal government's Office of Personnel Management--it's intuitively-based common sense.

3. "There were 24 items for each need system in the Inventory. The Work Motivation Inventory employs a scaling technique called the paired comparison format. In this format, (statements about the work environment which correspond with) each need is paired with (statements corresponding to) every other need a number of times, 


\section{Dispute on Motivation of Females}

and test respondents are asked to choose between the two or, as in the present case, to distribute 5 points between paired needs according to the degree of concern for each. Thus, each of the five need systems was measured relative to the remaining four; the needs which emerge as most strong have, in effect, won out when pitted against other need systems of less concern to the respondent" (Hall and Williams, 1967).

In the extreme (and unlikely) case of respondents who felt that one need system was very characteristic of their feelings (e.g., need for self-actualization), in contrast with another need system (e.g., physiological needs) which was seen as very uncharacteristic of their feelings, a point distribution of 5-0 would be made (other combinations would range from 4-1 and 3-2 through 0-5). Accordingly, respondents could have scored a maximum of 120 points $(24 \times 5)$ for each need system, from physiological through selfactualization. The fact that the Work Motivation Inventory has been administered to 20,452 persons from every conceivable work organization from across the nation allows for comparisons to be made between this sample of Arkansas female municipal employees and the national average.

4. E. g., "In general, the most important thing to me in evaluating a job is whether or not:

It pays well enough to satisfy the needs of my family and me or

It affords good job security and a strong program of employee benefits."

The first statement corresponds with physiological needs, the latter with safety-security needs.

5. Professor Herzberg cringes at comparisons such as this, arguing that it is like comparing apples and oranges, and that it distorts the utility of each typology. Still, the contrast between Herzberg and Maslow is commonly made in the literature and is specifically made by Hall and Williams, the authors of the tool employed in this study.

6. The author was a student of Professor Herzberg and is trained in these methods.

7. Herzberg's emphasis on "man" in this passage is a figurative expression applying only to all human beings in industrial societies. It is not a passage literally applying to men.

8. "Motivational inversions" are the psychological sicknesses which occur when we attempt to become fulfilled and satisfied in our work through the hygiene factors. It does not work, according to motivation-hygiene theory.

9. Eighty-five percent of the sample occupy full-time jobs, 15 percent have parttime positions. On a separate question, 63 percent said they are underpaid.

\section{References}

Ambrosius, Margery M. and Susan Welch (1984). "Women and Politics at the Grassroots: Women Candidates for State Office in Three States, 1950-1978," Social Science Journal. 21, 1:29-42.

Carroll, Berenice A. (1979). "Political Science, Part 1: American Politics and Political Behavior," Signs: Journal of Women in Culture and Society. 5, 2:289-306. 
Carroll, Susan J. (1984). "The Recruitment of Women for Cabinet-Level Posts in State Government: A Social Control Perspective," Social Science Journal 21, 1:91108.

Chernesky, Roslyn H. (1983). "The Sex Dimension of Organizational Processes: Its Impact on Women Managers," Administration in Social Work. 7, 3/4: 133-143.

Edwards, Carolyn P. and Beatrice B. Whiting (1974). "Women and Dependency," Politics and Society. 4, 3:343-350.

Elazar, Daniel J. (1972). American Federalism. 2nd ed. New York: Ths. Y. Crowell.

Feldman, Daniel C. and Hugh J. Arnold (1983). Managing Individuals and Group Behavior in Organizations. New York: McGraw-Hill.

Garcia, Jose Z., Cal Clark, and Janet Clark (1979). "Policy Impacts on Hispanics and Women: A State Case Study," in Marian L. Palley and Michael Preston (eds.), Race, Sex, and Policy Problems. Lexington, Mass: D.C. Heath and Co., Lexington Books.

Githens, Marianne and Jewel L. Prestage (1977). A Portrait of Marginality: The Political Behavior of the American Woman. New York: David McKay.

Gruberg, Martin (1984). "From Nowhere to Where? Women in State and Local Politics," Social Science Journal. 21, 1:5-12.

Haffron-Bers, Trudy (1978). "Local Political Elites: Men and Women on Boards of Education," Western Political Quarterly. 31, 3:381-392.

Hall, Jay and Martha Williams (1967). "Work Motivation Inventory Materials," Woodlands, Tx: Teleometrics International.

Herzberg, Frederick (1966). Work and the Nature of Man. New York: Ths. Y. Crowell. (1976). The Managerial Choice. Homewood, IL: Dow Jones-Irwin.

Jaquette, Jane S. (1976). "Review Essay, Political Science," Signs: Journal of Women in Culture and Society. 2, 1:147-164.

Key, V. O., Jr. (1949). Southern Politics in State and Nation. New York: Knopf.

Kincaid (Blair), Diane D. (1978). "Over His Dead Body: A Positive Perspective on Widows in the U.S. Congress," Western Political Quarterly. 31, 1:96-105.

Kotker, Z. (1980). "The 'feminine' Behavior of Powerless People," Savvy. 36-42.

Kranz, Harry (1976). The Participatory Bureaucracy: Women and Minorities in a More Representative Public Service. Lexington, Mass: D. C. Heath and Co., Lexington Books.

Kravetz, Diane and Linda E. Jones (1982). "Career Orientations of Female Social Work Students: An Examination of Sex Difference," Journal of Education for Social 
Work. 18, 3:77-84.

Lewis, Gregory B. (1986). "Race, Sex, and Supervisory Authority in Federal WhiteCollar Employment," Public Administration Review. 46, 1:25-30.

Maslow, Abraham H. (1943). "A Theory of Human Motivation," Psychological Review. 50:370-396.

(1954). Motivation and Personality. New York: Harper.

McCourt, Kathleen (1977). Working-Class Women and Grass-Roots Politics. Bloomington, Ind. : Indiana University Press.

McDonald, Jean G. and Vicky H. Pierson (1984). "Female County Party Leaders and the Perception of Discrimination: A Test of the Male Conspiracy Theory," Social Science Journal. 21, 1:13-20.

Neuse, Steven M. (1978). "Professionalism and Authority: Women in Public Service," Public Administration Review. 38, 5:436-441.

Pearson, S.S. (1981). "Rhetoric and Organizational Change: New Applications of Feminine Style," in B. L. Forisha and B. H. Goldman (eds.) Outsiders on the Inside. Englewood Cliffs, N. J. : Prentice-Hall.

Sapiro, Virginia (1983). The Political Integration of Women: Roles Socialization and Politics. Urbana: University of Illinois Press.

Savage, Robert L. and John P. Price (1980). "Regionalism in Two Southern States: an Exploratory Study of Intrastate Politicocultural Cleavages," Arkansas Political Science Journal. 1:25-49.

Simpson, Richard L. and Ida Simpson (1969). "Women and Bureaucracy in the SemiProfessions," in Amatai Etzioni (ed.) The Semi-Professions. New York: The Free Press.

Toren, Nina (1969). "Semi-Professionalism and Social Work: A Theoretical Perspective," in Amatai Etzioni (ed.) The Semi-Professions. New York: The Free Press.

Vertz, Laura L. (1985). "Women, Occupational Advancement, and Mentoring: An Analysis of One Public Organization," Public Administration Review. 45, 3:415423.

Wahba, M.A., \& Birdwell, L. G. (1976)" Maslow Reconsidered: A Review of Research on the Need Hierarchy Theory." Organization Behavior and Human Performance, 15, 212-240. 